\title{
Letter from the Editor-in-Chief: Growth of the Journal
}

\section{Maral Mouradian ${ }^{1}$}

Published online: 13 September 2019

(C) The American Society for Experimental NeuroTherapeutics, Inc. 2019

Neurotherapeutics, the official journal of the American Society for Experimental Neurotherapeutics, has gone through major growth and transformation since its launch in 2004. It began as a review journal, with each issue consisting of invited critical reviews that focus on a theme related to advancing therapeutics for neurological disorders. In 2011, the Journal began publishing unsolicited original research articles relevant to its mission in addition to the thematic reviews.

Since I assumed the role of Editor-in-Chief in 2014, the number of manuscript submissions has more than tripled, and the number of published research articles has quadrupled. In 2016, we also added the new feature of Current Perspectives to each issue. These invited manuscripts provide a platform for publishing points-of-view by key opinion leaders on current hot topics in neurologic therapeutics.

This growth has necessitated expanding the editorial leadership team. To that end, I am delighted to welcome Steven T. DeKosky, MD, who joins the Journal as Associate Editor effective with the current volume. Steve is Deputy Director of the McKnight Brain Institute, Aerts-Cosper Professor of Alzheimer's Research, and Professor of Neurology and Neuroscience at the University of Florida College of Medicine. He has a wealth of experience in academic neurology and neuroscience as a clinician, researcher, educator, and administrator. Steve joins two superbly skilled and dedicated Associate Editors: Gregory K. Bergey, MD, Professor of Neurology and Director of the Johns Hopkins Epilepsy

M. Maral Mouradian

mouradmm@rwjms.rutgers.edu

1 RWJMS Institute for Neurological Therapeutics and Department of Neurology, Rutgers - Robert Wood Johnson Medical School, Piscataway, NJ 08854, USA
Center, and Raymond A. Swanson, MD, Professor and Vice-Chair, Department of Neurology at the University of California, San Francisco.

I would like to take this opportunity to express my gratitude to members of our Editorial Board and external peer reviewers who are critical for maintaining the highest quality of publications. Thanks also to our Editorial Manager Linda Powell who continues to run the editorial office and ensures efficient handling of Journal tasks. In addition, our ongoing partnership with the production staff at Springer Nature allows for an effective collaboration to publish each issue of Neurotherapeutics.

As the current trajectory of growth continues, my colleagues on the editorial team and I look forward to maintaining rigorous peer review standards and publishing the latest research discoveries and authoritative reviews of broad interest on current and emerging treatments of neurological disorders.

M. Maral Mouradian, MD

Editor-in-Chief

Required Author Forms Disclosure forms provided by the authors are available with the online version of this article.

Publisher's Note Springer Nature remains neutral with regard to jurisdictional claims in published maps and institutional affiliations. 